\title{
COMPARATIVE STUDY BETWEEN PROXIMAL FEMORAL NAILING AND DYNAMIC HIP SCREW FIXATION
}

\author{
Inder Sain Gupta1, Sheetal2, Anurag Chabra ${ }^{3}$
}

${ }_{1}^{1}$ Associate Professor, Department of Orthopaedics, MAMC, Agroha.

${ }^{2}$ Associate Professor, Department of Anaesthesia, MAMC, Agroha.

3 Professor and HOD, Department of Orthopaedics, MAMC, Agroha.

\begin{abstract}
BACKGROUND

Hip fractures are usually common in elderly patients with osteoporosis intertrochanteric fracture accounting for approximately half of the hip fractures in these elderly patients, out of this more than $50 \%$ fractures are unstable. Internal fixation is appropriate for most intertrochanteric fractures, because of worldwide acceptance in the last 15 - 20 yrs. Dynamic hip screw (DHS) has behaved as the standard device and considered for comparison of outcomes. Though complications are few Dynamic hip screw has shown good results, specifically in stable intertrochanteric fracture. The proximal femoral nail's advantage over DHS is that it provides a more biomechanically stable construct, as there is reduced distance between implant and hip joint.

In this study, our main aim is to study the radiological and clinical result of PFN and DHS for treatment of intertrochanteric hip fracture, i.e. load sharing vs. load bearing device. The mainstay for treatment of intertrochanteric fracture is fixation with a proximal femoral nail or dynamic hip screw.
\end{abstract}

\section{MATERIALS AND METHODS}

A comparative study of 2 yrs. duration was conducted on 100 patients admitted in our hospital in Department of Orthopaedics with intertrochanteric fracture. They were treated by proximal femoral nail or with dynamic hip screw. Patients were treated under image intensifier control. The parameters considered in their study are Harris hip score, Duration of surgery, Blood loss during surgery, Intraoperative complication and Implant failure.

\section{RESULTS}

The average age of our patients was 65.2 years in both groups, 20 were male and 30 were female patients. The average blood loss in proximal femoral nail was around $120 \mathrm{~mL}$ and dynamic hip screw was around $250 \mathrm{~mL}$. Blood loss is less in PFN which is statistically significant, $\mathrm{P}$ value $<0.0001$. In PFN was more intraoperative radiation as compared to DHS. The average operating time for PFN was 48 mins and DHS it was around 70 mins, $\mathrm{P}<0.0001$. The patients with PFN started early mobilisation as compared to DHS, because of better Harris hip score.

\section{CONCLUSION}

In our study, we have found that unstable fracture pattern has better outcome with PFN as compared to DHS. PFN was found to have less operating time as well as less blood loss when compared to DHS. In PFN, early mobilisation is seen as compared to DHS.

\section{KEYWORDS}

Intertrochanteric Fractures; Dynamic Hip Screw; Proximal Femoral Nail.

HOW TO CITE THIS ARTICLE: Gupta IS, Sheetal, Chabra A. Comparative study between proximal femoral nailing and dynamic hip screw fixation. J. Evolution Med. Dent. Sci. 2018;7(06):759-762, DOI: 10.14260/jemds/2018/172

\section{BACKGROUND}

Hip fractures are usually common in elderly patients with osteoporosis. Intertrochanteric fracture account for approximately half of the hip fractures in these elderly patients, out of this more than $50 \%$ are unstable.

Gullberg et al(1) predicted that the total number of hip fractures will reach 2.6 million by 2025(2) and 4.5 million by 2050. In $199026 \%$ of all hip fractures occurred in Asia, whereas this figure could rise to $37 \%$ in 2025 and $45 \%$ in 2050. They are classified according to AO/OTA classification as A1 fractures are simple, two-part fractures. A2 fractures have multiple fragments and A3 fractures include reverse oblique and transverse fracture patterns.(3)

'Financial or Other Competing Interest': None.

Submission 14-07-2017, Peer Review 19-01-2018,

Acceptance 27-01-2018, Published 05-02-2018.

Corresponding Author:

Dr. Inder Sain Gupta,

H. No. 1054, Sector-14,

Hisar-125001, Haryana.

E-mail: isgupta79@gmail.com

DOI: $10.14260 /$ jemds $/ 2018 / 172$

\section{(c) $($ ) $\$$}

These fractures unite readily with conservative line of treatment, but there is fear of complications like malunion, shortening and osteoarthritis of hip joint. Earlier active treatment was usually delayed for 3 to 4 weeks, which lead to secondary complications.

They primarily involve cortical and compact cancellous bone. Because of the complex stress configuration in this region and its non-homogeneous osseous structure and geometry, fractures occur along the path of least resistance through the proximal femur.(4)

The treatment modality options for intertrochanteric fracture are operative as well as non-operative, though conservative treatment is not an option these days.

It is considered only in terminally ill patients, nonambulatory patients, low-life expectancy. It is also considered in patients with active infection, while options in early days where operative options were not evolved.(5)

The goal of treatment of any intertrochanteric fracture is to restore mobility safely and efficiently, while minimising the risk of medical complications and restore the patient to pre-operative status.(6) 
The goal of treatment of any intertrochanteric fracture is to provide early mobility and efficiently, while decreasing the risk of medical complications and restore the patient in preoperative stage. The dynamic hip screw (DHS) has gained widespread acceptance in the last two decades and is currently considered as the standard device for comparison of outcomes.

The DHS has been shown to produce good results, but complications are frequent, particularly in unstable fracture. The advantage of PFN is that it provides a more biomechanically stable construct by reducing the distance between hip joint and implant. The goal of this study is to compare the clinical radiological result of dynamic hip screw and proximal femoral nail for treatment of intertrochanteric fracture (load sharing vs. load bearing).

The Intramedullary Device have Distinct Advantages

- The intramedullary implant has reduced distance between implant and hip joint, i.e. shorter lever arm.

- The intramedullary device serves as buttress against lateral translation of proximal fragment.

- The intramedullary device is more biological method of fixation.

- The intramedullary implant has got higher resistance against the binding forces.

Therefore, study was conducted in MAMC Agroha to compare the results of fixation by these two methods.

\section{MATERIALS AND METHODS}

\section{According to A0/OTA Classification (Reference No. 8)}

- A1- Fractures are simple, two part fractures.

- A2- Fractures have multiple fragments.

- A3- Fractures include reverse oblique and transverse fracture patterns.

The following Type of Fracture or Patients were not included in the Study

- Patients with less than 2 years of follow-up.

- Pathological and bilateral fracture.

- Fracture that are associated with polytrauma.

- Any pre-existing femoral deformity and sub-trochanteric fracture.

The following were recorded in this Present Study of Intertrochanteric Fracture
a. Fracture type.
b. Age and sex.
c. Time for union.
d. Total surgical time.
e. Complications.

The decision for the type of operation was based purely on surgeon's preference and availability of the implant. All surgeries were performed on traction table following closed reduction confirmed with fluoroscopy on two different planes. All the cases included in our study was operated as soon as possible. The average delay of surgery in our study was 3 days.

For PFN, Nail diameter was determined by measuring diameter of the level of isthmus on an AP x-ray. Neck shaft angle was measured on an unaffected side in an AP x-ray using goniometer and a standard length PFN was used in all our cases.

For DHS, length of compression screw was measured from tip to the head of the base of greater trochanter on AP view $\mathrm{X}$-ray, subtracting magnification. Neck shaft angle was determined using goniometer on an AP view on an unaffected side and length of side plate was determined to allow purchase of at least 8 cortices distal to the fracture.

The clinical outcome for each group, all intraoperative early and late complications were noted. Patients followed up at regular intervals of 4 weeks/ 8 weeks/ 12 weeks/ 6 months and annually thereafter. The functional outcome assessed with Harris hip score parameters are-

\begin{tabular}{|c|c|}
\hline Parameters & Grading \\
\hline Pain & $<70$ points - Poor \\
\hline Limp & $70-79$ points - Fair \\
\hline Distance Walked & $80-89$ points - Good \\
\hline Support & $90-100$ points - Excellent \\
\hline \multicolumn{2}{|c|}{ Sitting } \\
\hline Enter public transportation \\
\hline Stairs \\
\hline Put on shoes and socks \\
Absence of deformity \\
Range of motion \\
\hline
\end{tabular}

\section{Statistical Analysis}

The Fisher exact test and unpaired ' $\mathrm{t}$ ' test were used to calculate and compare the group.

For all analysis, $\mathrm{P}<0.05$ was considered significant. Statistical analyses were performed using SPSS version 16.

\section{RESULTS}

- The study involved 100 confirmed cases of intertrochanteric fracture of either sex from 2013 2015. Out of 100 in Group 1 fifty were treated by DHS and in Group 2 fifty were treated by PFN.

- $\quad$ The average age was 65.2 years [SD + 4.21].

- The results were statistically analysed and were evaluated.

\section{Intraoperative Details/ Duration of Surgery}

- The duration of surgery was more in DHS as compared to PFN. The duration of surgery was calculated from time of incision to skin closure.

- The average time of surgery in PFN was 48 mins [SD + 2.3 ] and DHS was 70 mins [SD + 3.1], p value is $<0.0001$.

\section{Blood Loss during Surgery}

- Blood loss was measured by mop count and collection in suction drain.

- The average loss in PFN counts for $120 \mathrm{~mL}$ and in DHS it is $25 \mathrm{~mL}$, blood loss is less in PFN which is statistically significant with $P$ value $<0.0001$

\section{Intraoperative Complication}

- Patients with excellent result were 20 [37.5\%] in DHS group and 34 [66.2\%] in PFN.

- $\quad$ Patients with good results were 26 [54.1\%] in DHS and 15 [28.2\%] in PFN.

- Patients with fair result were $3[6.6 \%]$ in DHS and 1 [5.1\%] in PFN and patients with poor result was 1 [1.6\%] in DHS group and no patients with poor result in PFN group. 


\section{Overall Complication}

\begin{tabular}{|l|c|c|}
\hline \multicolumn{1}{|c|}{ Complication } & $\begin{array}{c}\text { PFN } \\
\text { (No. of } \\
\text { Patients) }\end{array}$ & $\begin{array}{c}\text { DHS } \\
\text { (No. of } \\
\text { Patients) }\end{array}$ \\
\hline Superficial infections & 0 & 2 \\
\hline Non-union & 1 & 1 \\
\hline Implant failure & 2 & 2 \\
\hline Deep infection & 0 & 1 \\
\hline
\end{tabular}

There were 3 cases of infections seen in the DHS group and were treated by local debridement and antibiotic and did not require implant removal. One which was acquired late required implant removal and was managed conservatively. No infection was seen in PFN group. Two cases of implant failure in PFN group and revision surgery was required for it. The usual ' $\mathrm{Z}$ ' pattern of implant failure was the reason. The case was treated by removal of cervical screw and refixation. In the DHS group, there were 2 cases of implant failure. One was due to screw cut-out and the other was due to plate breakage with non-union. In both the cases, revision surgery was required.
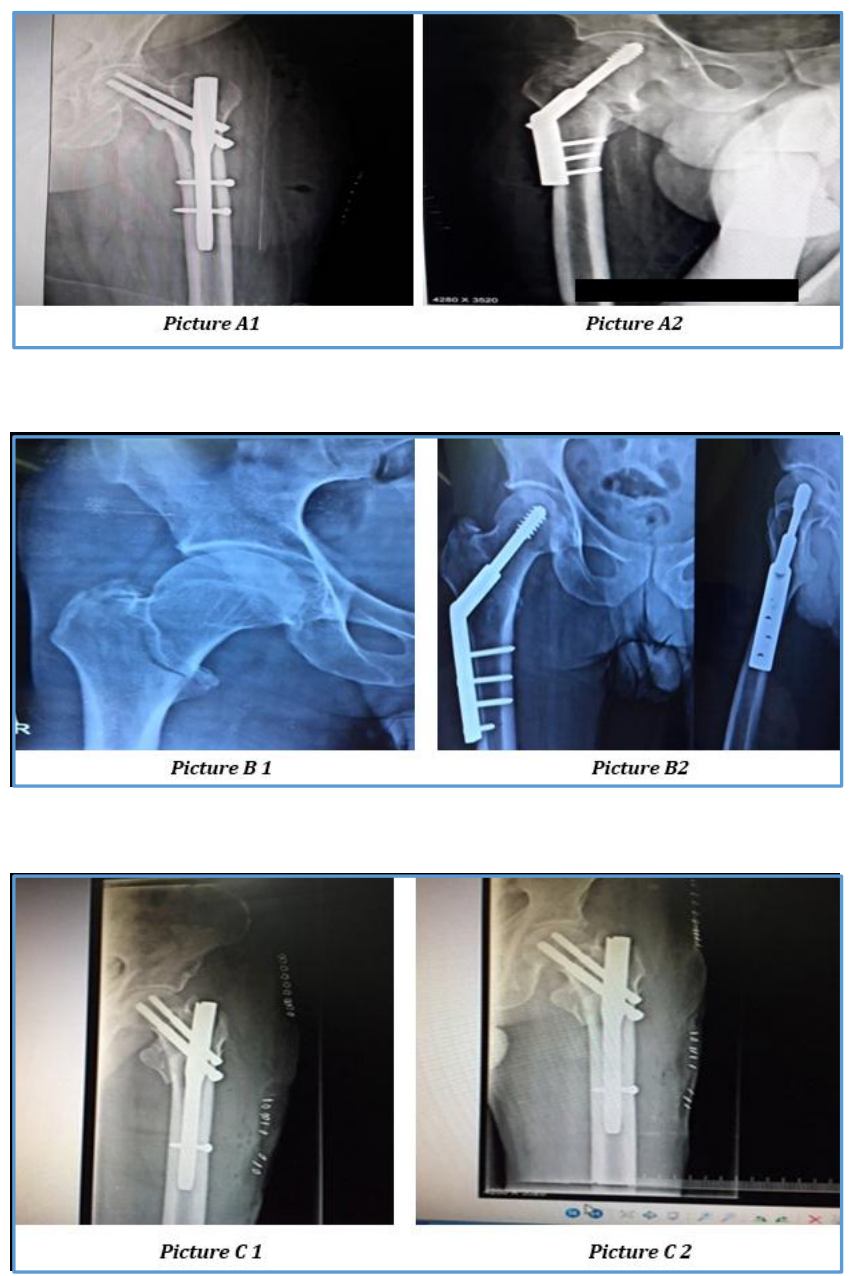

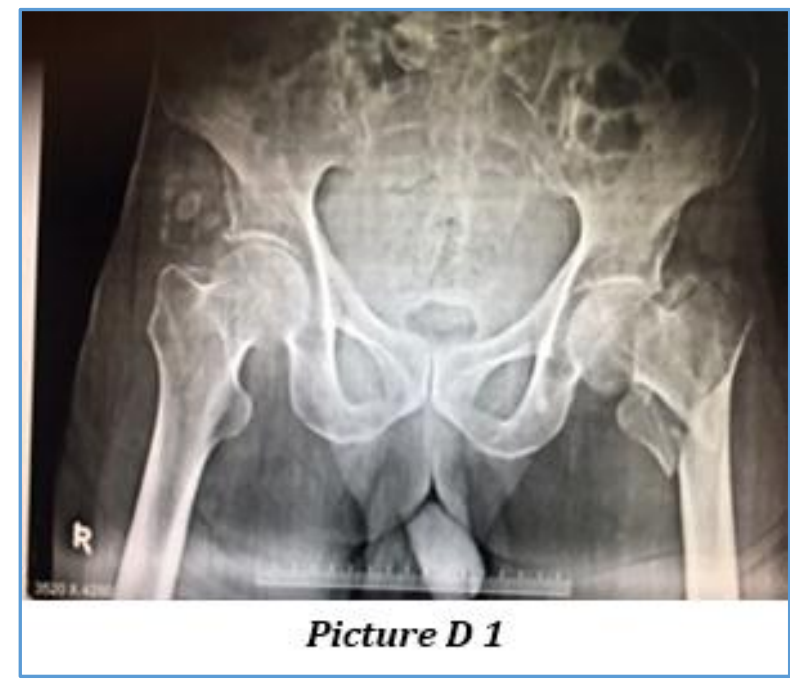

\section{DISCUSSION}

The development of the dynamic hip screw in the 1960's witnessed a revolution in the management of unstable fractures. It allowed compression of the fracture site without complications of screw cut-out and implant breakage associated with a nail plate. However, the extensive surgical dissection, blood loss and surgical time required for this procedure often made it a contraindication in the elderly with co-morbidities. The implant also failed to give good results in extremely unstable and the reverse oblique fracture.

In the early 90s, intramedullary devices were developed for fixation of Intertrochanteric fractures. These devices had numerous biomechanical and biological advantages over the conventional dynamic hip screw. 8 - 10 long term studies, however, revealed that the use of these devices was associated with higher intraoperative and late complication often requiring revision surgery. This has led to modifications in the device and technique of the intramedullary devices. (7)

Kulkarni et al reviewed the current concepts of treatment of intertrochanteric fractures. They concluded that unstable intertrochanteric fractures can be helped by intramedullary fixation, as there is more failure of dynamic hip screw. Boldin, Seibert et al in 2000 carried a prospective study of 55 patients having proximal femoral fractures treated with the proximal femoral nail. They achieved good results in most of the patients with very less complications at 12 months follow-up. They concluded that proximal femoral nail is a good minimal invasive implant for unstable proximal femoral fractures.

A comparison of intraoperative findings revealed no statistically significant differences between the study groups ( $\mathrm{P}=0.324$ for intraoperative complications). Total duration of surgery was significantly lower in PFN group than it was in DHS ( $\mathrm{p}<0.005)$. Incision size was lower in PFN group compared to DHS group ( $\mathrm{p}<0.05)$. A comparison of time to union demonstrated no statistically significant differences between study groups $(\mathrm{P}=0.542)$. Early and late postoperative complications were more in DHS group compared to PFN group. Functional outcome of unstable intertrochanteric fractures treated with PFN has significantly better outcomes with all having good results. 


\begin{tabular}{|l|c|c|}
\hline Complications & $\begin{array}{c}\text { No. of } \\
\text { Patients }\end{array}$ & $\mathbf{\%}$ \\
\hline Failure to achieve Closed Reduction & 4 & $7.84 \%$ \\
\hline Fracture of Lateral Cortex & 0 & 0 \\
\hline Failure to put Derotation Screw & 2 & $3.92 \%$ \\
\hline $\begin{array}{l}\text { Fracture Displacement by Nail } \\
\text { Insertion }\end{array}$ & 1 & $1.96 \%$ \\
\hline
\end{tabular}

\section{Functional Results of the Two Groups}

The sliding hip screw with plate remained the gold standard for fixation of intertrochanteric fractures for years with the arrival of the intramedullary hip screw. It was thought that the sliding hip screw would be replaced forever; however, this is not true. The intramedullary hip screw has its own set of complications, a higher learning curve and all at a higher cost. The sliding hip screw is still the implant of choice in the stable types of intertrochanteric fractures. If the proper intraoperative guidelines are adhered to, then the results in this group of patients is excellent. In the more unstable types of fracture, the PFN has distinct advantages over the plate and should be the preferred implant for fixation. The need to achieve an anatomical reduction is mandatory, since there is less sliding with this implant. Any gap on the post-operation $\mathrm{x}$-rays could always lead to a future non-union. PFN should be preferred in cases of severe osteoporosis, as it has got inherent stability and being intramedullary there is no question of screw pull-out which is a common complication in osteoporotic fractures treated with DHS. Finally, it could be stated that the implants are here to stay. It is the fracture geometry and bone quality that will influence the choice of fixation. The quality of the reduction and proper positioning of the implant are the keys in achieving the best postoperative outcome.

\section{CONCLUSION}

In our study, we have found that unstable fracture pattern have better outcome with PFN as compared to DHS. PFN was found to have less operating time as well as less of blood loss when compared to DHS. In PFN, early mobilisation is seen as compared to DHS.

\section{ACKNOWLEDGEMENTS}

We sincerely thank Dept. of Anaesthesia and Dr. Anurag Chabra, Professor, HOD, Dept. of Orthopaedics, MAMC, Agroha for helping us through the case series. Ever since we began this study, innumerable people have participated by contributing their time, energy and expertise. To each of them and to others whom we may have omitted through oversight, we owe a debt of gratitude for the help and encouragement. We express our gratitude to all the patients and their families who were the backbone of this study.

\section{REFERENCES}

[1] Gullberg B, Johnell O, Kanis JA. World-wide projection for hip fracture. Osteoporos International 1997;7(5):407-13.

[2] Melton LJ, Kearns AE, Atkinson EJ, et al. Secular trends in hip fracture incidence and recurrence. Osteoporosis International 2009;20(5):687-94.

[3] Lavelle DG. Fractures and dislocations of the hip. Chapter-52. In: Canale ST. edr. Cambell's Operative orthopaedics. Vol-3. 11 th edn. 2008:3237-308.

[4] Carter DR, Hayes WC. The compressive behavior of bone as a two - phase porous structure. The Journal of Bone \& Joint Surgery Am 1977;59(7):954-62.

[5] David A, Von Der Heyde D, Pommer A. Therapeutic possibilities in trochanteric fractures. Safe-fast-stable. Orthopade 2000;29(4):294-301.

[6] Nuber S, Schoweiss T, Ruter A. Stabilization of unstable trochanteric femoral fractures: dynamic hip screw (DHS) with trochanteric stabilization plate vs. proximal femoral nail (PFN). Journal of Orthopaedic Trauma 2003;17(4):316-7.

[7] Spivak JM, Zuckerman JD, Kummer FJ, et al. Fatigue failure of the sliding hip screw in hip fracture fixation: a report of three cases. Journal of Orthopaedic Trauma 1991;5(3):325-31. 